\title{
BMJ Open Digital telemedicine interventions for patients with multimorbidity: a systematic review and meta-analysis
}

\author{
Christian Kraef (D) , ${ }^{1}$ Marc van der Meirschen, ${ }^{2}$ Caroline Free ${ }^{3}$
}

To cite: Kraef C, van der Meirschen M, Free C. Digital telemedicine interventions for patients with multimorbidity: a systematic review and meta-analysis. BMJ Open 2020;10:e036904. doi:10.1136/ bmjopen-2020-036904

- Prepublication history and additional materials for this paper is available online. To view these files, please visit the journal online (http://dx.doi. org/10.1136/bmjopen-2020036904).

Received 09 January 2020 Revised 15 August 2020 Accepted 06 September 2020

A) Check for updates

(C) Author(s) (or their employer(s)) 2020. Re-use permitted under CC BY-NC. No commercial re-use. See rights and permissions. Published by BMJ.

${ }^{1}$ Heidelberg Institute of Global Health, University of Heidelberg, Heidelberg, Germany

${ }^{2}$ Department of Internal

Medicine, University Medical Center Hamburg-Eppendorf, Hamburg, Germany

${ }^{3}$ London School of Hygiene and Tropical Medicine Faculty of Epidemiology and Population Health, London, UK

Correspondence to

Dr Christian Kraef;

christiankraef@gmail.com

\section{ABSTRACT}

Objective To determine the effectiveness of digital telemedicine interventions designed to improve outcomes in patients with multimorbidity.

Design Systematic review and meta-analysis of available literature.

Data sources MEDLINE, EMBASE, The Cochrane Central Register of Controlled Trials, ClinicalTrials.gov, and the Database of Abstracts of Reviews of Effectiveness and hand searching. The search included articles from inception to 19 April 2019 without language restrictions. The search was updated on 7 June 2020 without additional findings.

Eligibility criteria Prospective interventional studies reporting multimorbid participants employing interventions with at least one digital telemedicine component were included. Primary outcomes were patient physical or mental health outcomes, health-related quality of life scores and the utilisation of health services.

Results Out of 5865 studies initially identified, 7 articles, reporting on 6 studies were retained (total of 699 participants). Four of these studies reported interventions including integration with usual care, two studies had interventions with no links to usual patient care. Followup periods lasted between 2 and 6 months. Among the studies with links to usual care, the primary outcomes were systolic blood pressure (SBP) (three studies), haemoglobin A1c (HbA1c) (three studies), total cholesterol (two studies) and self-perceived health status (one study). The evidence ranged from very low to moderate certainty. Meta-analysis showed a moderate decrease in SBP (8 mm Hg (95\% Cl 4.6 to 11.4)), a small to moderate decrease in $\mathrm{HbA1c}(0.46 \mathrm{mg} / \mathrm{dL}(95 \% \mathrm{Cl} 0.25$ to 0.67$))$ and moderate decrease in total cholesterol (cholesterol 16.5 $\mathrm{mg} / \mathrm{dL}(95 \% \mathrm{Cl} 8.1$ to 25.0$)$ ) in the intervention groups. There was an absence of evidence for self-perceived health status. Among the studies with no links to usual care, time to hospitalisation (median time to hospitalisation 113.4 days intervention and 104.7 days control group, absolute difference 12.7 days) and the Minnesota Living with Heart Failure Questionnaire (intervention group 35.2 score points, control group 23.9 points, absolute difference $11.3,95 \% \mathrm{Cl} 5.5$ to 17.1 ) showed small reductions. The Personal Health Questionnaire (PHQ-8) showed no evidence of improvement (intervention 7.6 points, control 8.6 points, difference 1.0 points, $95 \% \mathrm{Cl}-22.9 \%$ to $11.9 \%)$.

Conclusion Digital telemedicine interventions provided moderate evidence of improvements in measures of

\section{Strengths and limitations of this study}

Multimorbidity is an increasing global challenge and digital health solutions could contribute to improving care.

- Despite the attention given to digital health, no systematic review of digital health interventions for multimorbidity has been conducted before.

- Our systematic review shows that evidence for the effectiveness of digital telemedicine interventions for multimorbidity is very limited.

- Further high-quality studies are needed to create the necessary evidence base to inform guidelines and policy makers.

disease control but little evidence and no demonstrated benefits on health status. Further research is needed with clear descriptions of conditions, interventions and outcomes based on patients' and healthcare providers' preferences.

PROSPERO registration number CRD42019134872.

\section{INTRODUCTION}

The number of patients with multimorbidity is increasing globally and there is a recognised need to improve healthcare and outcomes for patients with multimorbidity. ${ }^{1}$ In Europe alone, more than 50 million people are affected, including $60 \%$ of those 65 years or older. ${ }^{12}$ Patients with multimorbidity have complex healthcare needs and are $40 \%$ more likely to report problems with care coordination than non-multimorbid patients. $^{3}$ Digital telemedicine interventions have in recent years increasingly been recognised as a useful tool that could help integrate and improve care for the complex health and social needs of multimorbid patients, for example, by 'encouragement of a new relationship between patient and health professional, enabling standardised information exchange between providers, and extending the scope of healthcare in a geographical and conceptual sense'. ${ }^{2}$ Most digital health research, however, has focused 
on single chronic diseases, patients with multimorbidity are often excluded from studies and reviews, and to date no, systematic review of the effectiveness of digital health interventions for patients with multimorbidity exists. ${ }^{45}$ In particular, a systematic review of the effectiveness on clinical and quality of life outcomes and the assessment of impact on use of healthcare systems is lacking. This is in particular reflected in the inadequacy of guidelines to support recommendations for managing multimorbid patients with digital telemedicine interventions. ${ }^{6}$ The WHO's recommendations on digital interventions for health systems strengthening highlight the need to ensure integration with existing healthcare structures to not inappropriately divert resources from alternative, non-digital approaches. ${ }^{7}$ Therefore, this review groups studies according to their integration with usual care.

\section{Objectives}

This study aimed to assess the effects of interventions with at least one digital telemedicine component designed to improve outcomes in patients with multimorbidity.

\section{METHODS}

Our systematic review was reported in accordance with the Preferred Reporting Items for Systematic Reviews and Meta-Analyses (PRISMA) statement for reporting of systematic reviews. ${ }^{8}$ The protocol for this review has been registered in the PROSPERO network (registration number: PROSPERO 2019 CRD42019134872).

\section{Patient and public involvement}

There was no patient or public involvement as this is a review of already published studies.

\section{Search strategy}

The databases MEDLINE and EMBASE, The Cochrane Central Register of Controlled Trials, ClinicalTrials.gov, and the Database of Abstracts of Reviews of Effectiveness were retrieved from inception to 19 April 2019 without language restrictions. The search was updated on 7 June 2020 without additional findings. In addition, reference lists of all papers and relevant reviews identified for relevant studies that the search might have missed were searched. The search strategy (see online supplemental appendix A) was developed based on the search terms for multimorbidity employed by the Cochrane review 'Interventions for improving outcomes in patients with multi-morbidity in primary care and community settings' and the search terms for e-health based on the Cochrane review 'eHealth interventions for people with chronic kidney disease'. ${ }^{49}$ The rationale for employing the search strategies from the Cochrane review 'Interventions for improving outcomes in patients with multimorbidity in primary care and community settings' is that the definition of multimorbidity is identical to the one used in our review (coexistence of multiple chronic diseases and medical conditions in the same individual; where chronic disease are health problems that require ongoing management over a period of year or decades). The same rationale underlies the use of the strategy on e-health which reflects the definition of e-health described above (eg, Telehealth, mobile phone (including text messaging and the use of applications on mobile phones), internet and computer, electronic monitors, and wireless and Bluetooth enabled devices).

\section{Study selection, inclusion and exclusion criteria \\ Types of studies}

Randomised controlled trials (RCTs), controlled clinical trials, designs controlled before and after studies and interrupted time series analyses were included. Studies published in all languages published through 19 April 2019 were included (updated on 7 June 2020).

\section{Types of participants}

People or populations with multimorbidity receiving care in all settings were included. Multimorbidity was defined as the coexistence of at least two chronic physical diseases in the same individual. The 11th International Classification of Diseases (ICD-11) was used to define disease. For the purposes of this review, studies that reported interventions for people with a mental health condition comorbid with only one physical intervention were excluded. We postulate that interventions for somatic and mental conditions usually differ in nature and therefore are very likely similar or the same as in patients with monomorbidity. However, studies that targeted mental health in additional to those with at least two physical conditions were included.



Figure 1 Preferred Reporting Items for Systematic Reviews and Meta-Analyses (PRISMA) flow diagram. The flow diagram depicts the flow of information through the different phases of a systematic review. 


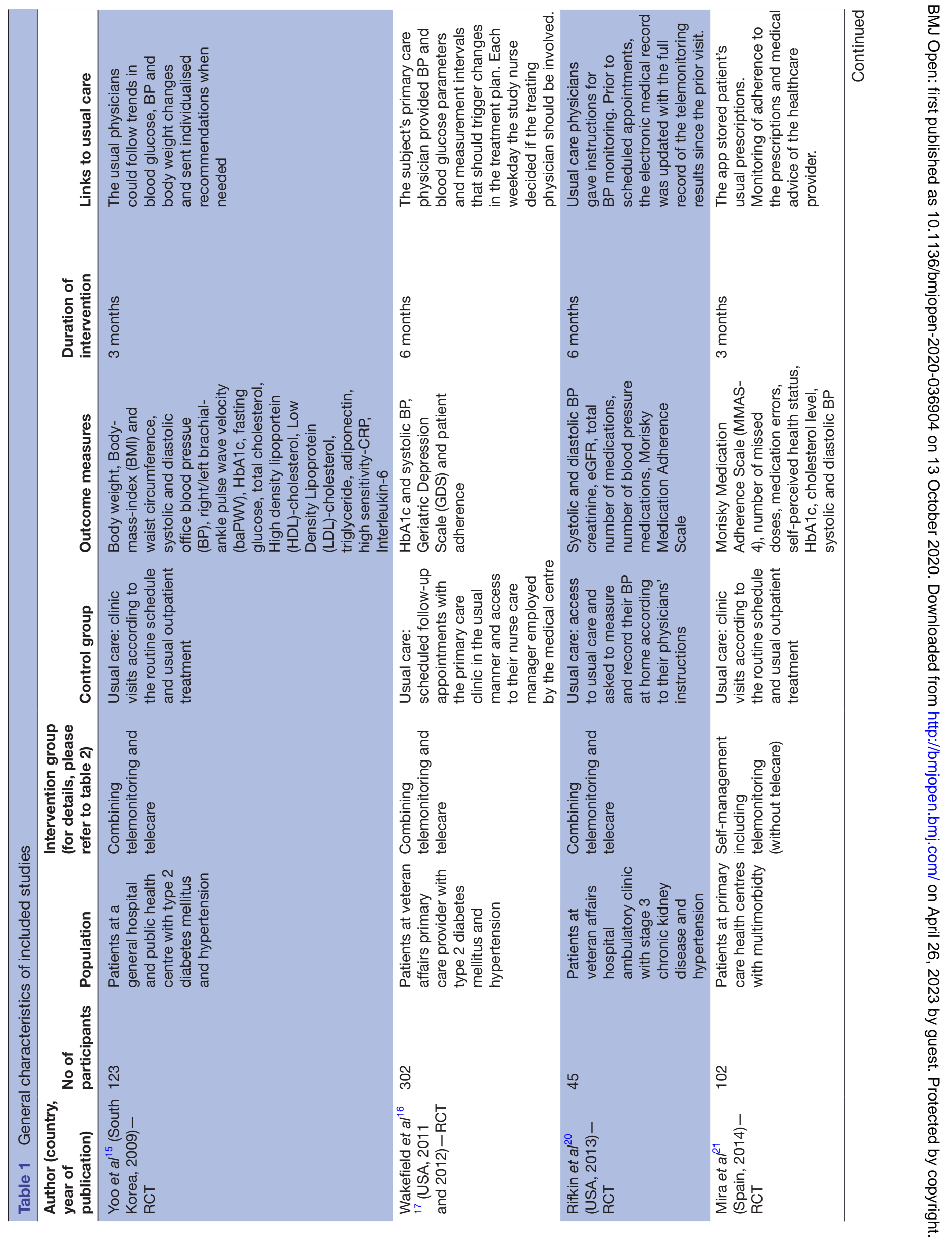




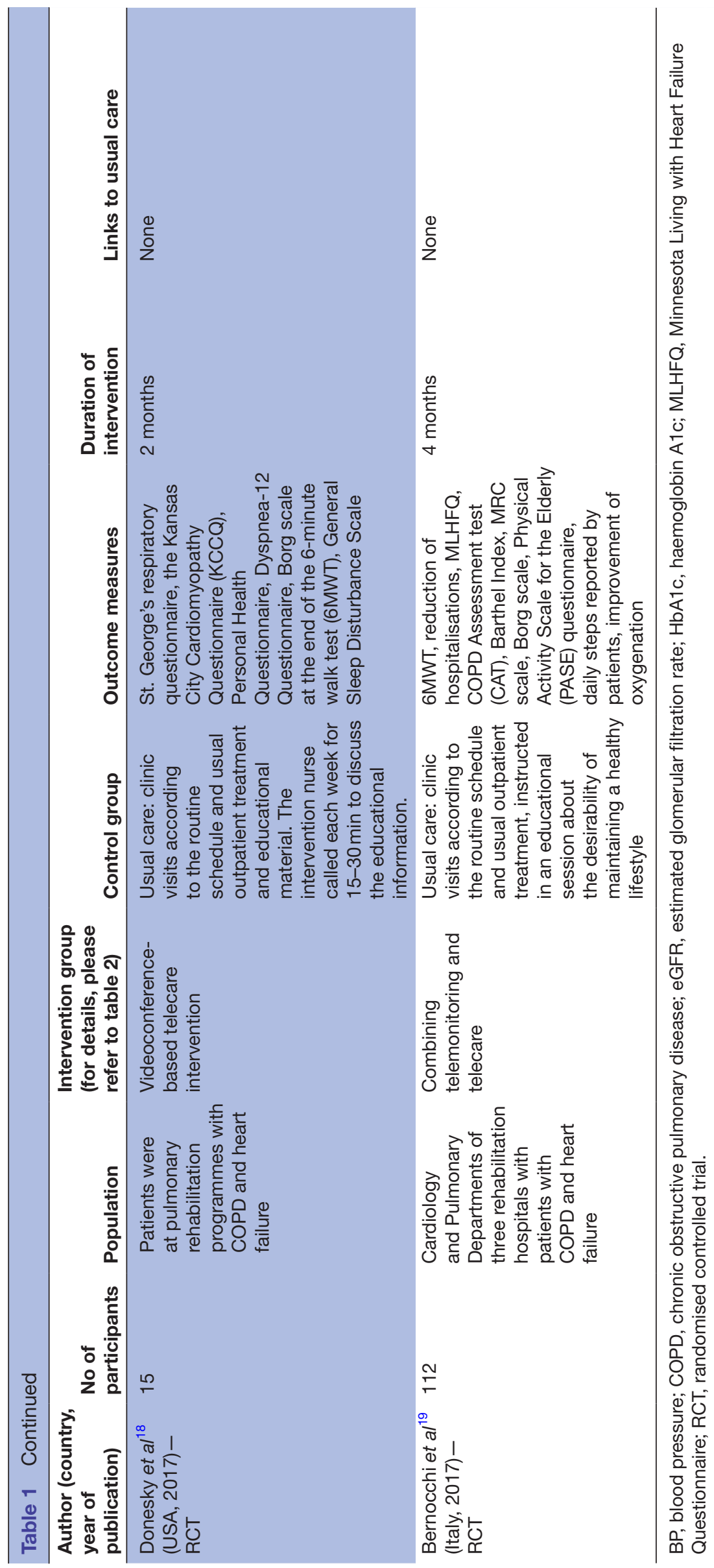




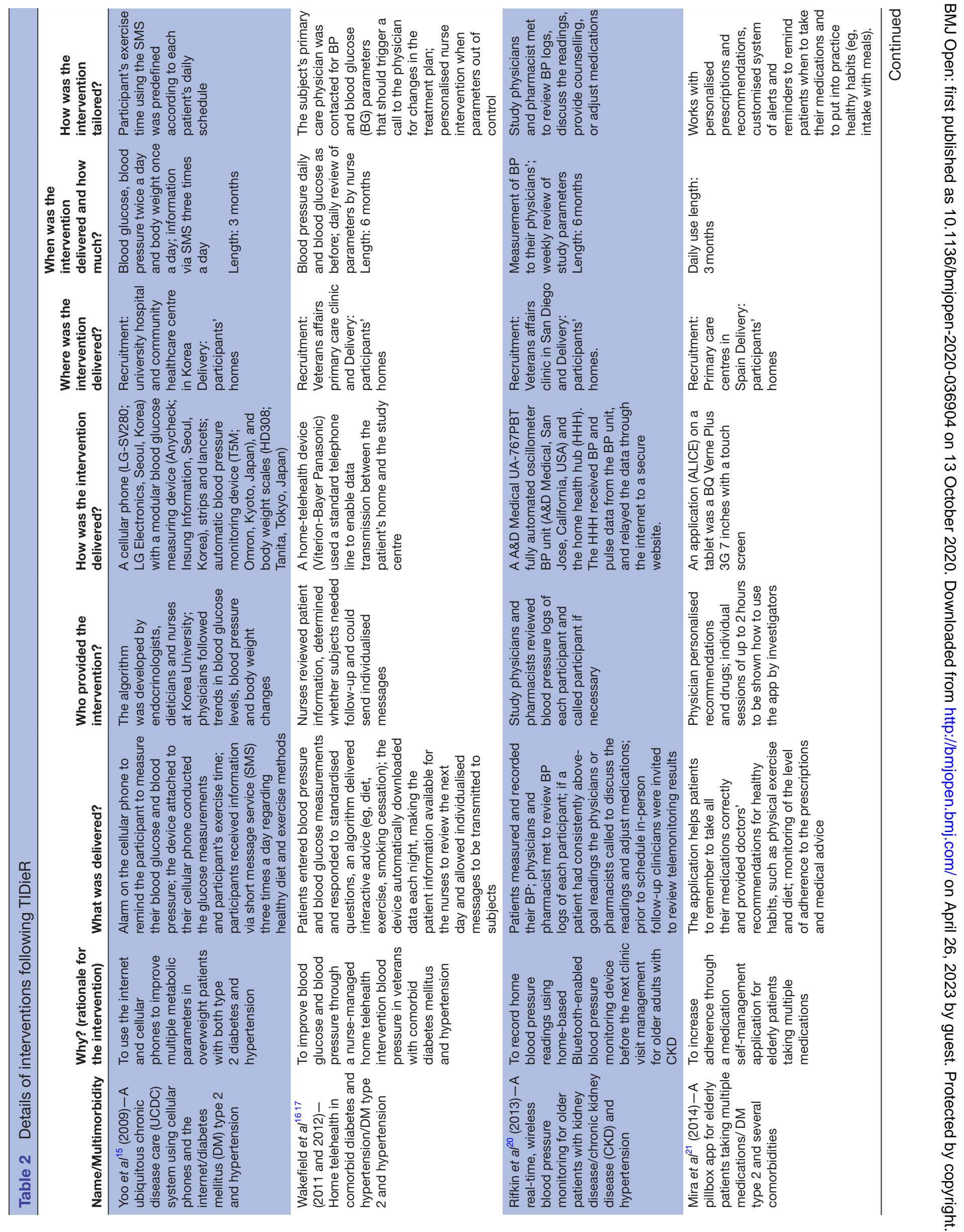




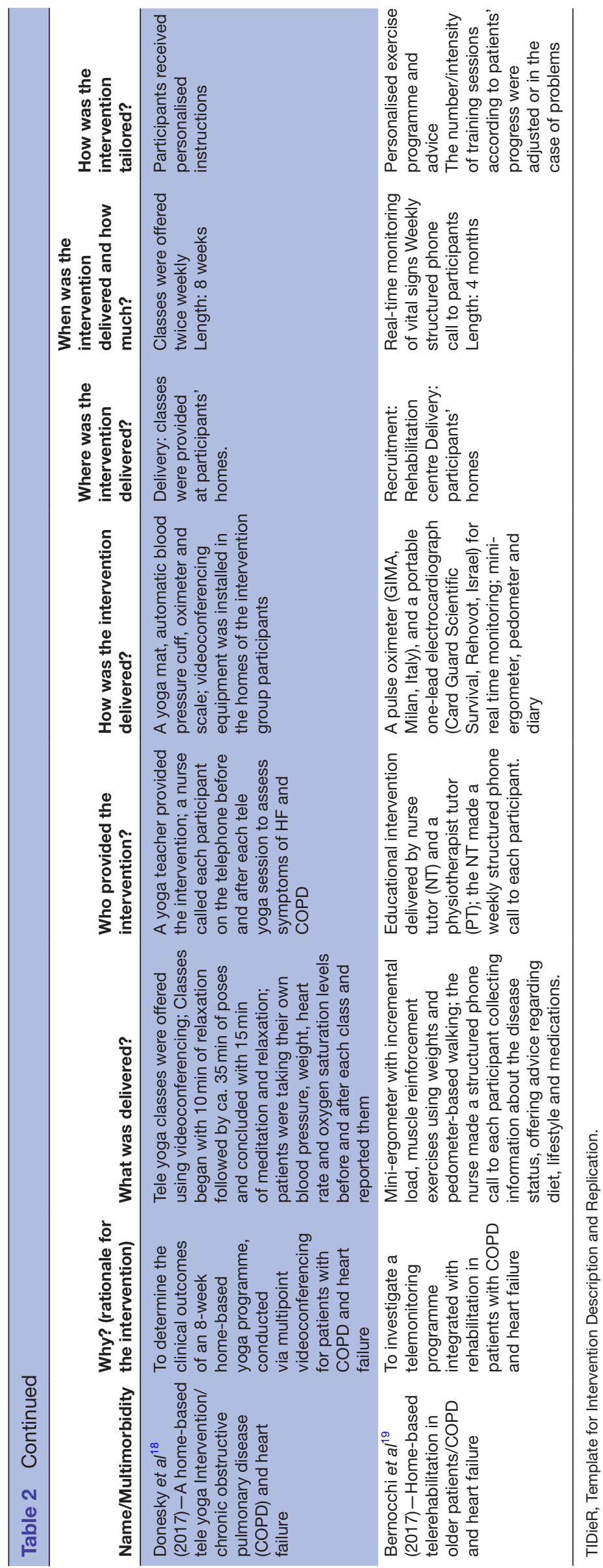


Table 3 Overview of primary and secondary outcomes

\begin{tabular}{|c|c|c|}
\hline $\begin{array}{l}\text { Outcome } \\
\text { category }\end{array}$ & $\begin{array}{l}\text { Outcome (Study reporting this } \\
\text { as primary outcome) }\end{array}$ & $\begin{array}{l}\text { No of } \\
\text { studies } \\
\text { with this } \\
\text { outcome }\end{array}$ \\
\hline \multirow{6}{*}{$\begin{array}{l}\text { Primary } \\
\text { outcomes }\end{array}$} & Blood pressure (systolic) & 3 \\
\hline & $\begin{array}{l}\text { HbA1c (Wakefield et al, } 2011 \text { and } \\
\text { 2012) }\end{array}$ & 3 \\
\hline & Cholesterol & 2 \\
\hline & Depression score & 1 \\
\hline & Health-related quality of life & 2 \\
\hline & Reduction of hospitalisations & 1 \\
\hline \multirow{6}{*}{$\begin{array}{l}\text { Secondary } \\
\text { outcomes } \\
\text { (details } \\
\text { in online } \\
\text { supplemental } \\
\text { file A) }\end{array}$} & $\begin{array}{l}\text { Physical functioning (Bernocchi } \\
\text { et al, 2018) }\end{array}$ & 2 \\
\hline & Self-efficacy & 1 \\
\hline & Dyspnoea & 2 \\
\hline & $\begin{array}{l}\text { Medication adherence (Mira et } \\
\mathrm{al}^{21} \text { ) }\end{array}$ & 3 \\
\hline & Levels of adiponectin & 1 \\
\hline & $\begin{array}{l}\text { Creatinine/estimated glomerular } \\
\text { filtration rate (eGFR) }\end{array}$ & 1 \\
\hline
\end{tabular}

\section{Types of interventions}

This review focuses on digital telehealth interventions as defined below. Effective interventions are likely to be complex and can consist of elements such as telemonitoring, telecare and self-management elements. ${ }^{4}$ Telemonitoring is defined as 'the remote monitoring of patients, including the use of audio, video, and other telecommunications and electronic information processing technologies to monitor patient status at a distance'. ${ }^{10}$ Telecare is the use of those data to provide clinical care, education and prevention at a distance, including remote consultation (eg, videoconferencing). ${ }^{11}$ Patient selfmanagement is defined as 'any intervention which aims to empower patients to be active decision makers who deal with emotional, social or medical management of their illness with the aim of improving their independence and Quality of Life'. ${ }^{12}$ Non-digital telemedicine interventions

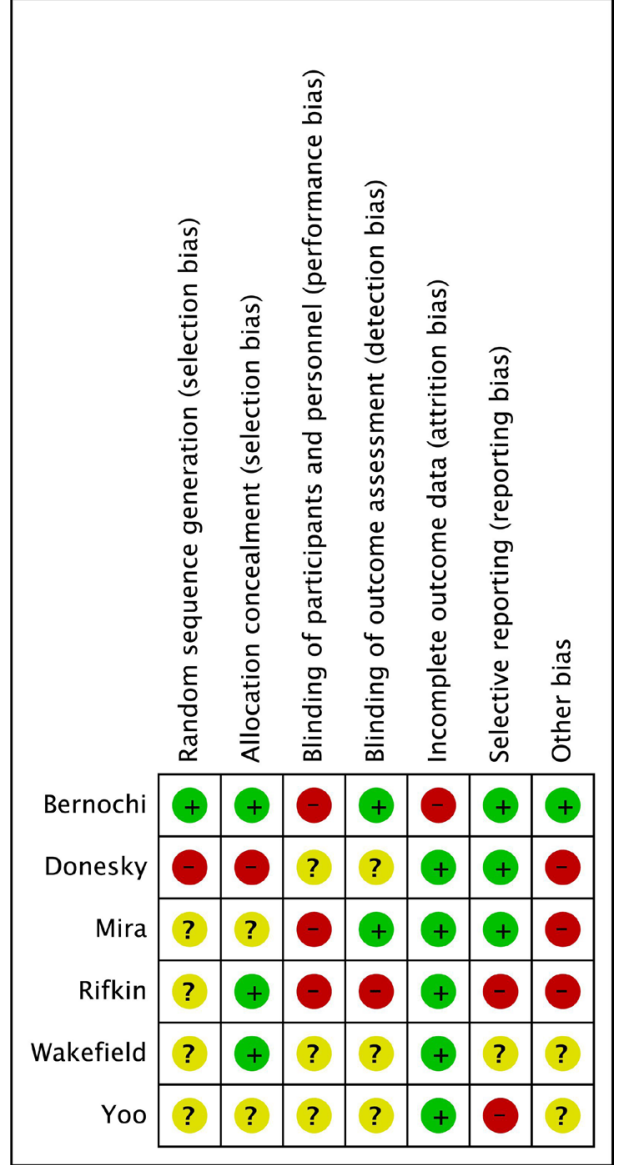

Figure 3 Risk of bias summary. Risk of bias summary: review authors' judgements about each risk of bias item for each included study.

(ie, connections only based on telephone) will not be included in this review. All interventions specifically direct towards patients with multimorbidity that had at least one digital telemedicine component as described above were included. The following interventions were excluded: (1) interventions focusing on healthcare management (eg, electronic health records), (2) interventions solely based on health data analytics (eg, clinical decision support systems), (3) interventions in which patients were not

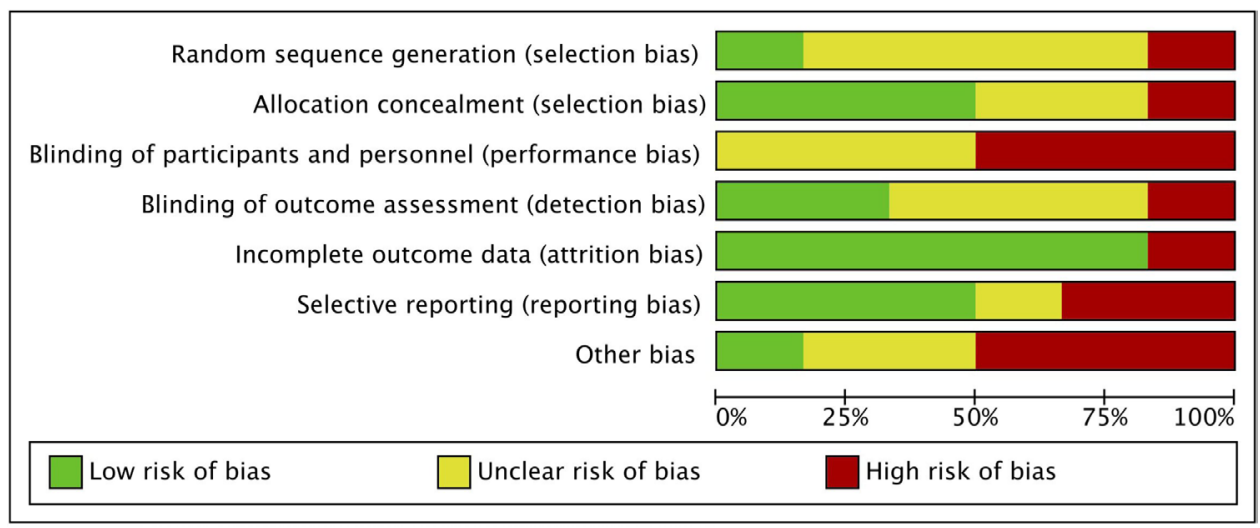

Figure 2 Risk of bias graph. Risk of bias graph: review authors' judgements about each risk of bias item presented as percentages across all included studies. 


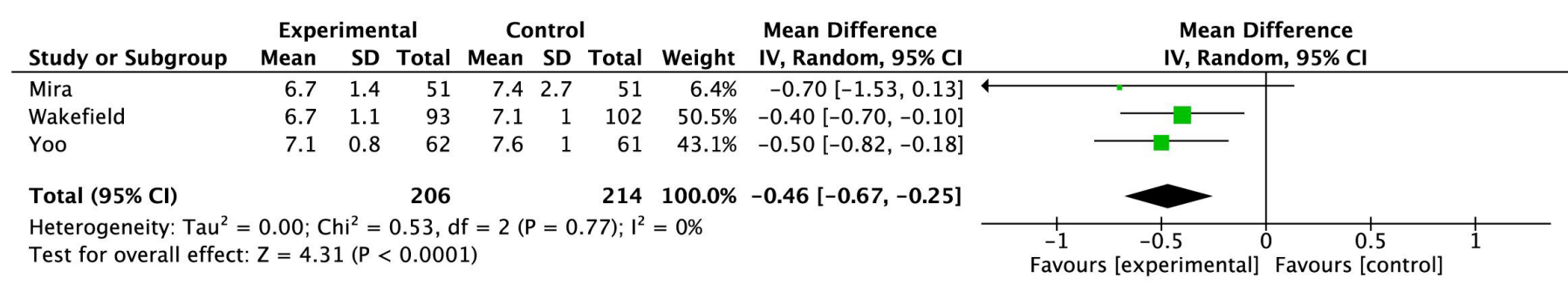

Figure 4 Meta-analysis for haemoglobin A1c (HbA1c) in mg/dL (including Wakefield high-intensity group). Forest plot of comparison: Digital telemedicine integrated with usual care compared with usual care, outcome: $\mathrm{HbA} 1 \mathrm{c}$ in $\mathrm{mg} / \mathrm{dL}$.

multimorbid according to our definition (eg, based on age or composite scores). To systematically describe the nature of the interventions, the different elements were analysed using the Template for Intervention Description and Replication (TIDieR) checklist. ${ }^{13}$

\section{Types of outcome measures}

Different combinations of diseases, as is the norm in multimorbidity, pose the challenge to define outcomes that can be used across studies and that are relevant to patients and care providers. Currently, no agreed on generic outcome measures incorporating relevant clinical or mental health outcomes exist. ${ }^{14}$ Therefore, important risk factors that are common to several prevalent diseases (blood pressure (BP), cholesterol and haemoglobin A1c (HbAlc)) were included as primary outcomes. As a major part of the burden of multimorbidity is caused by mental health problems (ie, depression), hospitalisations and reduced quality of life, these were also defined as primary outcomes. Secondary outcomes included self-efficacy, adherence to treatment and other psychosocial outcomes (see online supplemental appendix A).

Primary outcomes:

- Clinical outcomes (ie, BP, HbA1c, cholesterol).

- Mental health outcomes (depression scores).

- Health-related quality of life scores.

- Utilisation of health services (ie, hospitalisations).

Secondary outcomes:

- Patient psychosocial outcomes, including well-being and measures of disability or functional status.

- Patient behaviour including measures of medication adherence.

- Economic, including cost-effectiveness outcomes.

Attitude and knowledge outcomes were excluded.

\section{Data collection and analysis}

Potentially relevant studies were determined by concomitantly screening the titles and abstracts of search results by two authors. Full-text copies of all articles identified as potentially relevant were retrieved. Two review authors independently assessed each retrieved article for inclusion. There were no disagreements between the two authors. A flow diagram was developed using the PRISMA guidelines to display the search and selection process.

\section{Data extraction and management}

The following data were extracted for all included studies using a standardised form: a full description of the intervention including details regarding aims, evidence and/ or theory on which the intervention was based, nature of multimorbidity, information on the provider of the intervention, clinical setting, study design, results and whether the intervention was modified during the study.

\section{Risk of bias assessment}

Bias was assessed for randomised studies using the Cochrane risk of bias in intervention trials checklist (covering sequence generation, allocation concealment, blinding, incomplete outcome data and selective outcome reporting). A judgement of risk of bias on each of the tool's six domains was made from the extracted information, rated as 'high risk' or 'low risk'. If insufficient details were reported, the risk of bias was judged as 'unclear'.

\section{Data analysis}

Natural units were used for each study. Where outcomes were sufficiently clinically homogeneous (eg, systolic blood pressure (SBP) in $\mathrm{mm} \mathrm{Hg}$ ), a pooled meta-analysis was undertaken. A random-effects model was used to

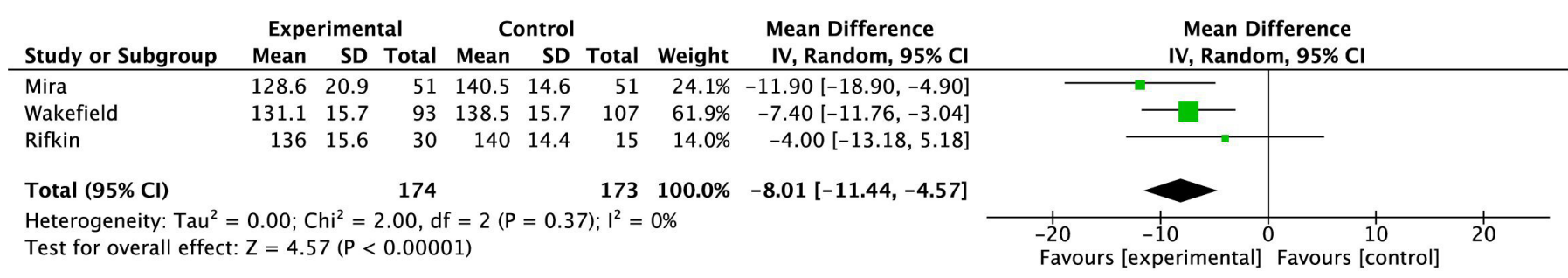

Figure 5 Meta-analysis for systolic blood pressure in $\mathrm{mm} \mathrm{Hg}$ (including Wakefield high-intensity group). Forest plot of comparison: Digital telemedicine integrated with usual care compared with usual care, outcome: systolic blood pressure in $\mathrm{mmHg}$. 




Figure 6 Meta-analysis for total cholesterol in $\mathrm{mg} / \mathrm{dL}$ (including Wakefield high-intensity group). Forest plot of comparison: Digital telemedicine integrated with usual care compared with usual care, outcome: total cholesterol in $\mathrm{mg} / \mathrm{dL}$.

account for statistical heterogeneity that cannot be explained by subgroup analysis or meta-regression (eg, due to too few studies). We used standardised effect sizes (SES) following the Cochrane handbook where studies reported relevant data for their calculation. The general convention was used that an SES of more than 0.2 indicates a small, 0.5 a moderate and more than 0.8 a large effect size. The program RevMan V.5 was used for conducting meta-analyses.

No unit of analysis error were found in the included studies. None of the included studies reported more than $15 \%$ of loss to follow-up or other sources of missing data. Therefore, no strategies for missing data were necessary. The evidence grade was determined using the Grading of Recommendations, Assessment, Development and Evaluation (GRADE) approach.

\section{RESULTS}

\section{Search results}

The electronic searches yielded 5865 articles after duplicates were removed (figure 1). A total of 5842 citations were excluded during screening of abstracts as they were not meeting the inclusion criteria. Full texts were retrieved for 23 studies. Of these, 16 studies were excluded during assessment of the full text and one was excluded during data extraction. Fourteen studies were excluded on the basis of not meeting the definition criteria for multimorbidity. One study was not an RCT and one was only published as a conference abstract of preliminary data (excluded studies in online supplemental appendix B). Seven articles from six studies were eligible for inclusion in this review.

\section{Characteristics of included studies}

We identified six RCTs eligible for inclusion in the review, reported in seven publications (Wakefield $(2011)^{1}$ and Wakefield (2012) ${ }^{2}$ reported different outcomes of the same trial) (table 1). No other eligible study designs were identified (detailed characteristics of included studies in online supplemental appendix $\mathrm{C}$ ). There was a total of 699 participants in the six included studies. Two studies involved participants with diabetes mellitus type 2 (DM type 2) and hypertension (Yoo et al $l^{15}$ and Wakefield $e t$ $\left.a l^{16}{ }^{17}\right)$, two studies patients with chronic obstructive pulmonary disease (COPD) comorbid with heart failure (Donesky et $a l^{18}$ and Bernocchi $e t a l^{19}$ ), one with chronic kidney disease (CKD) and heart failure (Rifkin et $a t^{20}$ ) and one with DM type 2 in combination with various other comorbidities (Mira $e t a l^{21}$ ). Three studies were set in primary care or home settings (Mira et al, ${ }^{21}$ Donesky et $a l^{18}$ and Bernocchi $e t a l^{19}$, two studies were set at Veteran affairs hospital outpatient clinics (Wakefield $e a^{1617}$ and Rifkin $e t a t^{20}$ ) and one was set at a university hospital and community health centres (Yoo et $\mathrm{al}^{15}$ ). Three studies were conducted in the USA (Wakefield et $a l^{16}{ }^{17}$ Rifkin et $a l^{20}$ and Donesky et $a l^{18}$ ), one study in South Korea, Spain and Italy respectively (Yoo $e t a l{ }^{15}$ Mira $e t a l^{21}$ and Bernocchi $e t$ $\left.a l^{19}\right)$. All studies were funded by government or university grants. None were funded by industry. In all included studies, the control group received usual medical care (comparator). In two studies, the control group furthermore received education/educational material (Donesky et $a l^{18}$ and Bernocchi $e t a l^{19}$ ).

\section{Assessment of interventions}

All interventions are multifaceted and described in detail in table 2. All the interventions identified involved at least one element of digital telemedicine. The interventions lasted 2 months (Donesky et $\mathrm{al}^{18}$ ), 3 months (Yoo et $a l^{15}$ and Mira et $\left.a l^{21}\right), 4$ months (Bernocchi et $a l^{19}$ ) and 6 months (Wakefield $e t a l^{1617}$ and Rifkin et $a l^{20}$ ). They could be divided into interventions combining telemonitoring and telecare (Yoo et al, ${ }^{15}$ Wakefield et al, ${ }^{16}{ }^{17}$ Rifkin et $a l^{20}$ and Bernocchi $e t a l^{19}$ ), self-management including telemonitoring (without telecare) (Mira $e t a l^{21}$ ), and a videoconference-based telecare intervention (Donesky et $a l^{18}$.

Four studies reported integration with usual care (Yoo et $a l,{ }^{15}$ Mira $e t a l,{ }^{21}$ Rifkin $e t a l^{20}$ and Wakefield $e t a l^{16}{ }^{17}$ ). Two studies had no elements of integration with usual care (Bernocchi et al ${ }^{19}$ and Donesky et $\mathrm{al}^{18}$ ). Table 1 shows how the interventions were integrated with the usual medical care of the participants.

\section{Description of outcomes}

Only three studies specifically defined and reported primary outcomes. HbAlc was reported in one study (Wakefield et $a l^{16}{ }^{17}$ ), exercise tolerance improvement measured by difference in the metres walked in the 6-minute walk test(6MWT) (Bernocchi et $\mathrm{l}^{19}$ ) and adherence to treatment measured by the 4-item Morisky Medication Adherence Scale (MMAS-4) (Mira et $a l^{21}$ ) in the other studies. Without specifying primary or secondary outcome, three studies reported the outcome systolic blood pressure (Wakefield et $a l^{1617}$ Rifkin $e t a l^{20}$ and Mira 
et $a l^{21}$ ). Three studies reported the outcome HbA1c (Yoo et $a l,{ }^{15}$ Wakefield $e t a l^{1617}$ and Rifkin et $\left.a l^{20}\right)$. Two studies reported the outcome total cholesterol (Mira $e t a l^{21}$ and Yoo $e t a l^{15}$ ). Two studies reported health-related quality of life outcomes (Bernocchi $e t a l^{19}$ and Mira $e t a l^{21}$ ). One study reported reduction of hospitalisations (Bernocchi $e t$ $a l^{19}$ ) and one study reported a depression score (Donesky $\left.e t a l^{18}\right)$. For an overview of reported outcomes, please refer to table 3. All studies reported outcomes at immediate postintervention follow-up. In addition, Wakefield $e t$ $a l^{1617}$ also reported outcomes after 12 months and Bernocchi et $a l^{19}$ after 3 months. No study reported proper economic outcomes or analysis.

\section{Risk of bias across studies}

Only one study reported all elements for the risk of bias domains. Four studies reported two or more domains with a high risk of bias. One study had four domains with a high risk of bias (figures 2 and 3). Four studies (Bernocchi $e$ t al ${ }^{19}$ Donesky et al,${ }^{18}$ Rifkin $e t a l^{20}$ and Wakefield $e t$ $a l^{1617}$ ) reported information on allocation concealment. There was a high risk of bias in one study (Donesky et $a l^{18}$ ) due to open allocation of intervention and control groups. Baseline outcome measurements were conducted in all studies. Performance bias (blinding of participants and personnel) was unclear (not reported) in three studies (Donesky et al, ${ }^{18}$ Wakefield et al, ${ }^{16}{ }^{17}$ Yoo et $a l^{15}$ ) and was judged as high risk in three studies (Bernocchi $e t$ $a l,{ }^{19}$ Mira $e t a l,{ }^{21}$ Rifkin $e t a l^{20}$ ) because participants could not be blinded due to the nature of the interventions. Detection bias was unclear in the same three studies (Donesky et $a l^{18}{ }^{18}$ Wakefield $e t a l^{1617}$ and Yoo et $a l^{15}$ ) and was judged as low risk in two studies (Bernocchi et al ${ }^{19}$ and Mira $e t a l^{21}$ ) and as high risk in one study (Rifkin $e t$ $\left.a l^{20}\right)$ as the assessors of the outcome were not blinded. All studies reported sufficient information to assess the risk of attrition bias. Five studies (Donesky et al, ${ }^{18}$ Mira et $a l^{21}$ Rifkin et $a l^{20}$ Wakefield $e t a l^{1617}$ and Yoo et $a l^{15}$ ) were judged as of low risk for attrition bias. One study (Bernocchi et $a l^{19}$ ) was rated as high risk of attrition bias due to high loss to follow-up unbalanced between the two groups. Five studies reported sufficient information to judge bias on selective reporting. Three (Bernocchi $e t$ $a l,{ }^{19}$ Donesky $e t a l^{18}$ and Mira $\left.e t a l^{21}\right)$ were judged as low risk for selective reporting bias. One study was judged as unclear (Wakefield $e t a l^{1617}$ ) and one study (Rifkin et $a l^{20}$ ) was rated as of high risk of bias because of no prespecified outcome parameters; no prepublished protocol or prespecified outcomes described in the Methods section. Three studies reported high risk of other bias (Donesky $e t$ $a l^{18}$ Mira $e t a l^{21}$ and Rifkin $\left.e t a l^{20}\right)$ due to further selection bias and unexplained elements for outcome reporting.

\section{Studies integrated with usual care}

Three studies reported HbAlc (Yoo et al ${ }^{15}$, Wakefield $e t$ $a l^{1617}$ and Mira et $a l^{21}$ ) and systolic blood pressure (Rifkin et $a l^{20}$, Wakefield $e t a l^{1617}$ and Mira $\left.e t a l^{11}\right)$ as outcomes, while two studies reported total cholesterol changes (Yoo et $a l^{15}$ and Mira $\left.e t a l^{11}\right)$. Meta-analysis showed a moderate decrease in SBP of $8 \mathrm{~mm} \mathrm{Hg}$ (95\% CI 4.6 to 11.4, test for overall effect $\mathrm{p}<0.0001$, moderate certainty evidence) (figure 4), a small to moderate decrease in HbAlc of $0.46 \mathrm{mg} / \mathrm{dL}(95 \% \mathrm{CI} 0.25$ to 0.67 , test for overall effect $\mathrm{p}<0.0001$, moderate certainty evidence) (figure 5) and moderate decrease in total cholesterol of $16.5 \mathrm{mg}$ / $\mathrm{dL}(95 \%$ CI 8.1 to 25.0 , test for overall effect $\mathrm{p}<0.0001$, moderate certainty evidence) (figure 6) in the intervention groups. No relevant heterogeneity was detected in the meta-analyses. Taking SBP as an example, we found the largest effect on the outcome in Mira et $a l^{20}$ (absolute difference $12.1 \mathrm{~mm} \mathrm{Hg}$ ), followed by Wakefield et $a l^{1617}$ (absolute difference $7.4 \mathrm{~mm} \mathrm{Hg}$ ) and Rifkin $e t a l^{20}$ (absolute difference $4.0 \mathrm{~mm} \mathrm{Hg}$ ). The intervention in Mira $e t$ $a l^{20}$ was a tablet-based application to increase adherence for medication self-management for elderly patients taking multiple medications while the control group received clinic visits according to the routine schedule and usual outpatient treatment. In Wakefield et al, ${ }^{1617}$ the intervention consisted of a nurse-managed home telehealth intervention where patients with hypertension and diabetes entered BP and blood glucose measurements regularly and responded to standardised questions. An algorithm delivered interactive advice (eg, diet, exercise, smoking cessation) and allowed individualised messages to be transmitted to subjects. The control group received scheduled follow-up appointments with the primary care clinic in the usual manner and access to their nurse care manager employed by the medical centre. The smallest effect size was observed in the study of Rifkin $e t a l,{ }^{20}$ where the intervention consisted of a real-time, wireless blood pressure monitoring for patients with hypertension and chronic kidney disease and physicians and pharmacist that review BP logs of each participant to discuss the readings and adjust medications if necessary. The control grozp received access to usual care and BP measurements at home. All interventions had in common that they increased the frequency that patients were reminded of measuring or treating their BP. In the least effective study, the control group was also asked to measure their own BP more regularly, possibly this could have lead to a reduced difference in effect.

One study (Mira $e t a l^{21}$ ) reported a quality of life outcome (self-perceived health status) with a small and non-significant standardised effect size $(69.1 \%$ in control and $74.6 \%$ in intervention group, difference in proportions $5.4 \%, 95 \%$ CI $-22.9 \%$ to $11.9 \%$ ). Table 4 shows the details for clinical outcomes and table 5 shows the summary of findings for studies with links to usual care.

\section{Studies not integrated with usual care}

One study (Donesky et $a l^{18}$ ) reported a mental health outcome, the Personal Health Questionnaire-8 (PHQ-8), one study (Bernocchi $e t a l^{19}$ ) reported reduction of hospitalisations and quality of life scores (Minnesota Living with Heart Failure Questionnaire (MLHFQ) score) as an outcome ( 8 and 12 weeks) (table 6 ). There was no 
Table 4 Clinical outcomes in studies with links to usual care

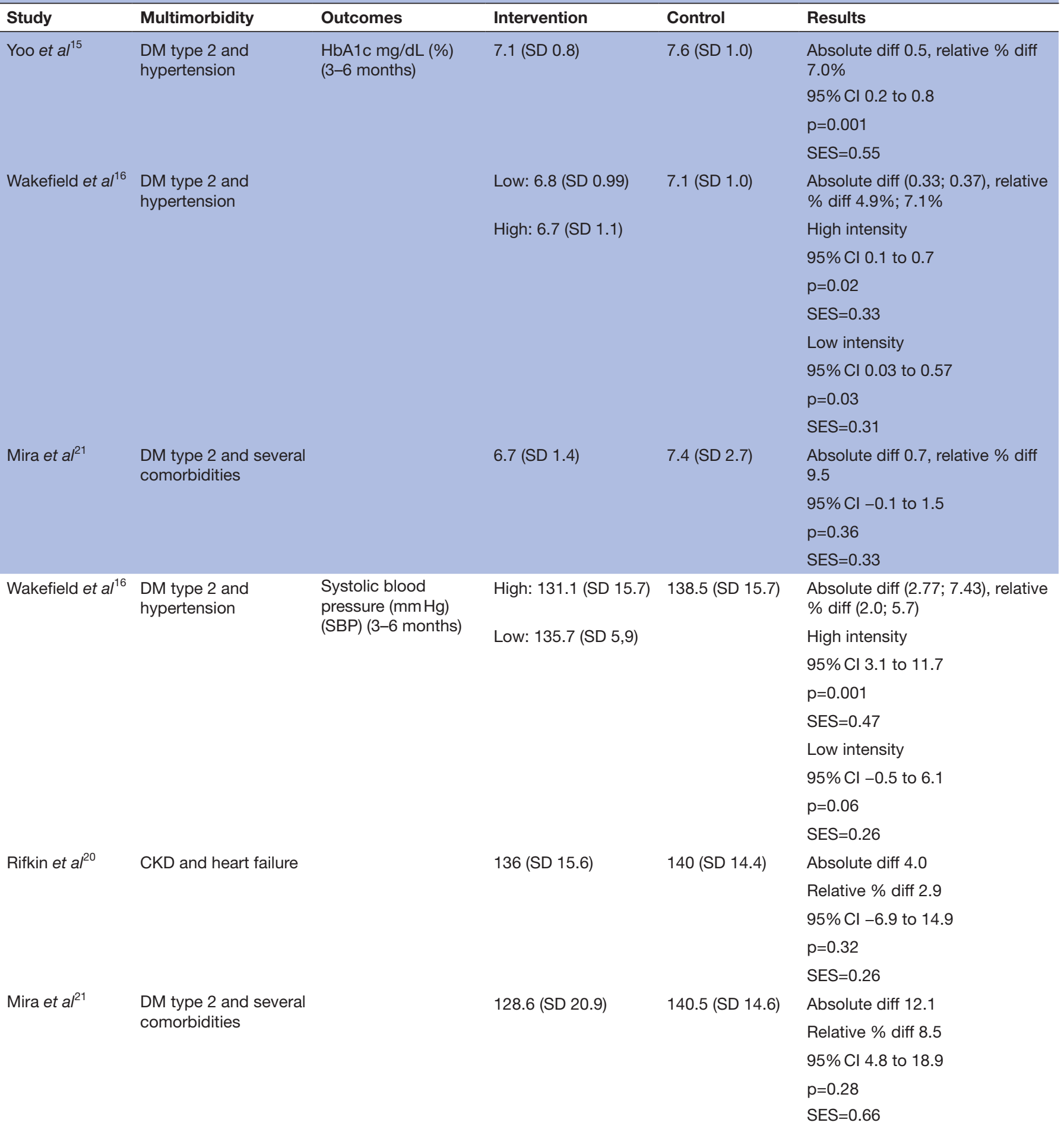

Continued 


\begin{tabular}{|c|c|c|c|c|c|}
\hline Study & Multimorbidity & Outcomes & Intervention & Control & Results \\
\hline Mira et $a l^{21}$ & $\begin{array}{l}\text { DM type } 2 \text { and several } \\
\text { comorbidities }\end{array}$ & $\begin{array}{l}\text { Total cholesterol (mg/ } \\
\mathrm{dL})(3 \text { months) }\end{array}$ & 101.9 (SD 28.1) & 112.7 (SD 45.8) & $\begin{array}{l}\text { Absolute diff } 10.8 \\
\text { Relative \% diff } 9.6 \\
95 \% \mathrm{Cl}-4.1 \text { to } 25.7 \\
\mathrm{p}=0.04 \\
\text { SES }=0.28\end{array}$ \\
\hline Yoo et al $1^{15}$ & $\begin{array}{l}\text { DM type } 2 \text { and } \\
\text { hypertension }\end{array}$ & & 154.7 (SD 27.1) & 174.0 (SD 30.9) & $\begin{array}{l}\text { Absolute diff } 19.3 \text {, } \\
\text { Relative } \% \text { diff } 9.8 \% \\
95 \% \mathrm{Cl} 8.9 \text { to } 29.7 \\
\mathrm{p}=0.011 \\
\mathrm{SES}=0.53\end{array}$ \\
\hline
\end{tabular}

CKD, chronic kidney disease; HbA1c, haemoglobin A1c; SES, standardised effect size.

significant effect size for the PHQ-8 outcome (intervention 7.6 points, control 8.6 points, difference 1.0 points, $95 \%$ CI $-22.9 \%$ to $11.9 \%$ ). Among the studies with no links to usual care hospitalisations (median time to hospitalisation 113.4 days intervention group vs 104.7 days control group, absolute difference $=12.7$ days, $\mathrm{p}=0.048$, moderate certainty evidence), the MLHFQ (intervention group 35.2 score points, control group 23.9 points, absolute difference $11.3,95 \%$ CI 5.5 to $17.1, \mathrm{p}=0.007$, moderate certainty evidence) showed a small reduction. The Personal Health Questionnaire (PHQ-8) showed no improvement ( $\mathrm{p}=0.48$, very low certainty evidence). Table 6 shows the details for primary outcomes, and table 7 shows the summary of findings table for studies without links to usual care. The certainty of the evidence for the depression score (PHQ-8) was downgraded to very low due to high risk of bias and imprecision (only 15 participants in the trial) (Donesky et $a^{18}$ ). The certainty of the evidence for reduction of hospitalisations was moderate and downgraded due to serious risk of bias. The quality of life outcome (MLHFQ) had a moderate to large effect size and moderate certainty of the evidence due to serious risk of bias.

\section{DISCUSSION}

In light of the increasing role of digital health in the global health policy debate, we offer for the first time a systematic overview of interventional studies that assess digital telemedicine interventions for multimorbidity. Four studies had strong links to usual care. Among those studies, metaanalysis showed a moderate decrease in SBP of $8 \mathrm{~mm} \mathrm{Hg}$ (moderate certainty evidence) in patients with diabetes mellitus and hypertension, a small to moderate decrease in $\mathrm{HbA} 1 \mathrm{c}$ of $0.46 \mathrm{mg} / \mathrm{dL}$ (moderate certainty evidence) in patients with diabetes and chronic kidney disease as indicator diseases and moderate decrease in total cholesterol of $16.5 \mathrm{mg} / \mathrm{dL}$ (moderate certainty evidence) in the intervention groups in patients with diabetes and hypertension. However, there was an absence of evidence for self-perceived health status (low certainty evidence). Among the studies with no links to usual care hospitalisations (moderate certainty evidence), the MLHFQ (moderate certainty evidence) showed a small reduction. The Personal Health Questionnaire (PHQ-8) showed no evidence for improvement (very low certainty evidence). No evaluation of costs or cost-effectiveness was provided in the available articles. This is an important element for future studies as to determine the effectiveness of the interventions, costs are a necessary aspect to be in consideration.

Many studies reported a large number of outcomes, without clearly defining primary and secondary outcomes. There was only evidence for a very limited number of multimorbid diseases (diabetes mellitus, hypertension, COPD), leaving an evidence gap for most patients with other conditions. The definition of multimorbidity used in this review requires patients to have at least two physical diseases and does not include patients in which only one physical disease co-occurs with a diagnosed mental disease. This excludes a number of studies where multimorbidity is defined more broadly but for which interventions likely are very different. The lack of clearly defined primary outcomes in the included studies, together with the consistent lack of sample-size calculations and small numbers of participants across studies, leads to a very high risk of underpowered studies and false-positive observed effects. The short and varying follow-up times between 2 and 6 months may have implications as the measured 
Table 5 Summary of findings table for studies with links to usual care

Summary of findings for the main comparison

Patient or population: Patients with multimorbidity

Setting: All settings/digital telemedicine with links to usual care

Intervention: Digital telemedicine

Comparison: Normal care

\begin{tabular}{|c|c|c|c|c|c|c|}
\hline \multirow[t]{2}{*}{ Outcomes } & \multicolumn{2}{|c|}{$\begin{array}{l}\text { Anticipated absolute effects }(95 \% \\
\text { Cl) }\end{array}$} & \multirow{2}{*}{$\begin{array}{l}\text { Mean } \\
\text { Standardised } \\
\text { effect size }\end{array}$} & \multirow[t]{2}{*}{$\begin{array}{l}\text { No of participants } \\
\text { (studies) }\end{array}$} & \multirow[t]{2}{*}{$\begin{array}{l}\text { Certainty of the } \\
\text { evidence (GRADE) }\end{array}$} & \multirow[t]{2}{*}{ Comments } \\
\hline & $\begin{array}{l}\text { Risk with } \\
\text { normal care }\end{array}$ & $\begin{array}{l}\text { Risk with digital } \\
\text { telemedicine }\end{array}$ & & & & \\
\hline $\begin{array}{l}\text { Systolic blood pressure } \\
\text { (SBP) follow-up: range 3-6 } \\
\text { months }\end{array}$ & $\begin{array}{l}\text { The mean } \\
\text { systolic blood } \\
\text { pressure was } \\
139.7 \mathrm{~mm} \mathrm{Hg}\end{array}$ & $\begin{array}{l}\text { MD } 8 \mathrm{~mm} \mathrm{Hg} \\
\text { lower ( } 4.6 \text { lower } \\
\text { to } 11.4 \text { lower) }\end{array}$ & Moderate (0.5) & 347 (3 RCTs) 162021 & $\begin{array}{l}\oplus \oplus \oplus \bigcirc \\
\text { MODERATE† } \ddagger \S ~ १\end{array}$ & $\begin{array}{l}\text { Types of multimorbidity: } \\
\text { diabetes mellitus and } \\
\text { hypertension }(2 x) \\
\text { and diabetes mellitus } \\
\text { and several other } \\
\text { comorbidities }\end{array}$ \\
\hline
\end{tabular}

\begin{tabular}{|c|c|c|c|c|c|c|}
\hline $\begin{array}{l}\text { Haemoglobin } \mathrm{A} 1 \mathrm{c}(\mathrm{HbA} 1 \mathrm{c}) \\
\text { assessed with: } \mathrm{mg} / \mathrm{dL} \\
\text { (\%) follow-up: range 3-6 } \\
\text { months }\end{array}$ & $\begin{array}{l}\text { The mean } \\
\text { haemoglobin A1c } \\
\text { was } 6.8 \mathrm{mg} / \mathrm{dL}\end{array}$ & $\begin{array}{l}\text { MD } 0.46 \mathrm{mg} / \mathrm{dL} \\
\text { lower }(0.25 \text { lower } \\
\text { to } 0.67 \text { lower })\end{array}$ & $\begin{array}{l}\text { Small to } \\
\text { moderate } \\
(0.41)\end{array}$ & 420 (3 RCTs) $)^{162021}$ & $\begin{array}{l}\oplus \oplus \oplus \bigcirc \\
\text { MODERATE } § ~ १\end{array}$ & $\begin{array}{l}\text { Types of multimorbidity: } \\
\text { diabetes mellitus and } \\
\text { hypertension, diabetes } \\
\text { mellitus and several other } \\
\text { comorbidities, chronic } \\
\text { kidney disease and heart } \\
\text { failure }\end{array}$ \\
\hline $\begin{array}{l}\text { Total cholesterol assessed } \\
\text { with: } \mathrm{mg} / \mathrm{dL} \text { follow-up: } \\
\text { mean } 3 \text { months }\end{array}$ & $\begin{array}{l}\text { The mean total } \\
\text { cholesterol was } \\
128.3 \mathrm{mg} / \mathrm{dL}\end{array}$ & $\begin{array}{l}\text { MD } 16.5 \mathrm{mg} / \mathrm{dL} \\
\text { lower ( } 8.1 \text { lower } \\
\text { to } 25 \text { lower) }\end{array}$ & $\begin{array}{l}\text { Moderate } \\
(0.48)\end{array}$ & $225(2 \mathrm{RCTs})^{20} 21$ & $\begin{array}{l}\oplus \oplus \oplus \bigcirc \\
\text { MODERATE† ‡ ๆ }\end{array}$ & $\begin{array}{l}\text { Types of multimorbidity: } \\
\text { diabetes mellitus and } \\
\text { hypertension and } \\
\text { diabetes mellitus } \\
\text { and several other } \\
\text { comorbidities }\end{array}$ \\
\hline $\begin{array}{l}\text { Self-perceived health } \\
\text { status assessed with: } \\
\text { proportion perceiving their } \\
\text { health status as good or } \\
\text { very good follow-up: mean } \\
3 \text { months }\end{array}$ & $\begin{array}{l}\text { The mean self- } \\
\text { perceived health } \\
\text { status was } \\
69.1 \%\end{array}$ & $\begin{array}{l}\text { Mean } 74.6 \% \\
\text { higher }\end{array}$ & Small (0.3) & $102(1 \mathrm{RCT})^{21}$ & $\oplus \oplus \bigcirc \bigcirc$ LOW§ ๆ ** & $\begin{array}{l}\text { Type of multimorbidity: } \\
\text { diabetes mellitus } \\
\text { and several other } \\
\text { comorbidities }\end{array}$ \\
\hline
\end{tabular}

Wakefield et al (2012).

GRADE Working Group grades of evidence.

High certainty: We are very confident that the true effect lies close to that of the estimate of the effect.

Moderate certainty: We are moderately confident in the effect estimate: The true effect is likely to be close to the estimate of the effect, but there is a possibility that it is substantially different.

Low certainty: Our confidence in the effect estimate is limited: The true effect may be substantially different from the estimate of the effect Very low certainty: We have very little confidence in the effect estimate: The true effect is likely to be substantially different from the estimate of effect.

${ }^{\star}$ The risk in the intervention group (with $95 \% \mathrm{Cl}$ ) is based on the assumed risk in the comparison group and the relative effect of the intervention (with $95 \% \mathrm{Cl}$ ).

†Risk of bias due to lack of blinding of outcome assessment (detection bias).

$\ddagger$ Risk of bias due to selective outcome reporting (reporting bias).

$\S$ Risk of bias due to lack of blinding of participants and personnel (performance bias).

IImportant biases were not adequately reported in the studies (unclear risk).

${ }^{\star *}$ Small number of participants and wide Cls.

$\mathrm{MD}$, Mean difference.

outcomes can be transient and not sustainable in the longer term. A majority of studies had a serious risk of bias in at least two domains, in particular lack of blinding and selective outcome reporting. This is compounded by the small number of relevant randomised studies $(n=6)$ with very few participants $(n=699)$ that were not well conducted. An assessment of small study publication bias was not possible due to the heterogeneity of studies. In summary, the generalisability of our findings is limited. All of the studies in this review were published within the last 10 years, in high-income countries in privileged socioeconomic environments and with elderly patients, which is very likely due to the fact that digital technologies and e-Health interventions have only become more widespread and available recently. Increasingly, multimorbidity is becoming a problem of younger patients and people in low-income and middle-income countries which are currently not covered by the available evidence base.

It is difficult to examine the effect of the single elements of the interventions that contributed most to the pooledeffect sizes across studies. Interventions that included links to usual care reported larger benefits. This is consistent with our assumption at the outset that given that participants have multiple morbidity and more complex health needs, it seems highly likely that to be more effective in the long-term interventions would need to be linked to usual care (eg, through using electronic health records, involving physicians and nurses in goal setting, regular information exchange). We would also anticipate that links to usual care would be needed for interventions 


\begin{tabular}{|c|c|c|c|c|c|}
\hline Study & Multimorbidity & Outcomes & Intervention & Control & Results \\
\hline Donesky et $a l^{18}$ & $\begin{array}{l}\text { COPD and heart } \\
\text { failure }\end{array}$ & $\begin{array}{l}\text { Personal Health } \\
\text { Questionnaire- } 8 \text { score ( } 8 \\
\text { weeks) }\end{array}$ & 7.2 (SD 6.3) & 8.6 (SD 6.0) & $\begin{array}{l}\text { Absolute diff } 1.4 \\
\text { Relative \% diff } 16.3 \\
95 \% \mathrm{Cl}-22.9 \% \text { to } \\
11.9 \% \\
\mathrm{p}=0.48 \\
\mathrm{SES}=0.22\end{array}$ \\
\hline $\begin{array}{l}\text { Bernocchi et } \\
a l^{19}\end{array}$ & $\begin{array}{l}\text { COPD and heart } \\
\text { failure }\end{array}$ & $\begin{array}{l}\text { Reduction of } \\
\text { hospitalisations - median } \\
\text { time in days ( } 12 \text { weeks) }\end{array}$ & 113.4 & 104.7 & $\begin{array}{l}\text { Absolute diff } 12.7 \\
\text { Relative \% diff } 8.3 \\
p=0.048 \\
\text { SES }=0.38\end{array}$ \\
\hline & & $\begin{array}{l}\text { Minnesota Living with Heart } \\
\text { Failure Questionnaire score } \\
\text { (12 weeks) }\end{array}$ & 32.8 (SD 14.2) & 35.5 (SD 10.3) & $\begin{array}{l}\text { Absolute diff } 2.7 \\
\text { Relative } \% \text { diff } 7.6 \\
95 \% \mathrm{Cl}-1.9 \text { to } 7.3 \\
\mathrm{p}=0.409 \\
\mathrm{SES}=0.22\end{array}$ \\
\hline
\end{tabular}

COPD, chronic obstructive pulmonary disease; SES, standardised effect size.

to be safe, although we have no evidence from the systematic review regarding safety. However, for hypertension, the interventions that increased the frequency patients gave attention to measuring their BP or taking medication regularly showed the largest effect sizes. Therefore, we postulate that some of the observed effect of the digital telemedicine interventions might be due to reminding the patients of their disease and the respective treatment combined with increased self-monitoring. Selfmonitoring has previously been shown to improve disease management for single diseases such as hypertension. ${ }^{22}$ However, a plausible but undocumented side effect might include reduced quality of life due to an increased focus on morbidity.

A recent Cochrane review of interventions for improving outcomes in patients with multimorbidity in primary care and community settings similar to this review also only found a small number of relevant studies. ${ }^{4}$ The authors concluded that interventions need to target specific risk factors in order to be effective. These findings are in line with the findings of this review that the effective interventions target specific common risk factors of many multimorbid diseases such as BP or cholesterol. The results of this review are also in agreement with studies of telemedicine interventions targeting specific individual risk factors such as BP where 'several randomised studies have documented a significant BP reduction with regular BPT compared with usual care and where additional benefits are observed when BPT is offered under the supervision of a team of healthcare professionals' (the mean systolic reduction was larger in the telemonitoring group by $5 \mathrm{~mm} \mathrm{Hg}$, compared with $8 \mathrm{~mm} \mathrm{Hg}$ in our review). ${ }^{23}$ Similar positive effects were observed for the effect of e-health and m-health interventions on HbAlc (pooled difference in $\mathrm{HbAlc}$ means $=-0.37 \mathrm{mg} / \mathrm{dL}$ for e-health and $-0.27 \mathrm{mg} / \mathrm{dL}$ for mobile phone, compared with $-0.46 \mathrm{mg} / \mathrm{dL}$ in our review). ${ }^{24}{ }^{25}$ Two further Cochrane reviews of e-health interventions for anxiety and depression in children and adolescents with long-term physical conditions and of eHealth interventions for people with chronic kidney disease concluded that the evidence for e-health intervention was of low quality, with randomised trials with uncertain effects due to the heterogeneity of interventions and outcomes. ${ }^{9}{ }^{26}$ This supports an important conclusion of this review that future research needs to identify outcomes that are relevant to patients and needs to investigate which individual elements of interventions are effective.

Usually the management of multimorbidity is defined by multiple appointments, potentially competing treatment goals, and non-integrated care services for patients and multiple guidelines, challenges of prioritisation coordination with other professionals. ${ }^{27}$ In summary, digital telemedicine interventions could improve the management of multimorbidity. However, overall, our findings suggest that current evidence for the use of digital 
Table 7 Summary of findings table for studies without links to usual care

\section{Digital telemedicine compared with normal care in multimorbidity care}

Patient or population: Patients with multimorbidity

Setting: All settings - digital telemedicine without links to usual care

Intervention: Digital telemedicine

Comparison: Normal care

\begin{tabular}{|c|c|c|c|c|c|c|}
\hline \multirow[t]{2}{*}{ Outcomes } & \multicolumn{2}{|c|}{$\begin{array}{l}\text { Anticipated absolute effects } \\
(95 \% \mathrm{Cl})\end{array}$} & \multirow{2}{*}{$\begin{array}{l}\text { Mean } \\
\text { standardised } \\
\text { effect size }\end{array}$} & \multirow{2}{*}{$\begin{array}{l}\text { No of } \\
\text { participants } \\
\text { (studies) }\end{array}$} & \multirow{2}{*}{$\begin{array}{l}\text { Certainty of } \\
\text { the evidence } \\
\text { (GRADE) }\end{array}$} & \multirow[t]{2}{*}{ Comments } \\
\hline & $\begin{array}{l}\text { Risk with } \\
\text { normal care }\end{array}$ & $\begin{array}{l}\text { Risk with digital } \\
\text { telemedicine }\end{array}$ & & & & \\
\hline $\begin{array}{l}\text { Personal Health } \\
\text { Questionnaire-8 } \\
\text { score (PHQ-8 score) } \\
\text { assessed with: } \\
\text { score follow-up: } \\
\text { mean } 8 \text { weeks }\end{array}$ & $\begin{array}{l}\text { The mean } \\
\text { Personal Health } \\
\text { Questionnaire-8 } \\
\text { score was } 8.6 \\
\text { score points }\end{array}$ & $\begin{array}{l}\text { Mean } 7.6 \text { score } \\
\text { points }\end{array}$ & Small (0.22) & $15(1 \mathrm{RCT})^{18}$ & $\begin{array}{l}\oplus \bigcirc \bigcirc \bigcirc \\
\text { VERY LOW† } \\
\ddagger \S \emptyset\end{array}$ & $\begin{array}{l}\text { Type of } \\
\text { multimorbidity: } \\
\text { chronic } \\
\text { obstructive } \\
\text { pulmonary } \\
\text { disease (COPD) } \\
\text { and heart failure }\end{array}$ \\
\hline $\begin{array}{l}\text { Reduction of } \\
\text { hospitalisations } \\
\text { assessed with: } \\
\text { median time in days } \\
\text { follow-up: mean } 12 \\
\text { weeks }\end{array}$ & \multicolumn{2}{|c|}{$\begin{array}{l}\text { Median time until hospitalisation in } \\
\text { the intervention group: } 113.4 \text { days } \\
\text { control group: } 104.7 \text { days }\end{array}$} & Small (0.38) & $112(1 \mathrm{RCT})^{19}$ & $\begin{array}{l}\oplus \oplus \oplus \bigcirc \\
\text { MODERATE } \\
\dagger \dagger\end{array}$ & $\begin{array}{l}\text { Type of } \\
\text { multimorbidity: } \\
\text { COPD and heart } \\
\text { failure }\end{array}$ \\
\hline
\end{tabular}

GRADE Working Group grades of evidence.

High certainty: We are very confident that the true effect lies close to that of the estimate of the effect.

Moderate certainty: We are moderately confident in the effect estimate: The true effect is likely to be close to the estimate of the effect, but there is a possibility that it is substantially different.

Low certainty: Our confidence in the effect estimate is limited: The true effect may be substantially different from the estimate of the effect. Very low certainty: We have very little confidence in the effect estimate: The true effect is likely to be substantially different from the estimate of effect.

${ }^{*}$ The risk in the intervention group (with $95 \% \mathrm{Cl}$ ) is based on the assumed risk in the comparison group and the relative effect of the intervention (with $95 \% \mathrm{Cl}$ ).

†Important biases were not adequately reported in the studies (unclear risk).

$\ddagger$ Risk of bias due to lack of random sequence generation (selection bias).

$\S$ Risk of bias due to lack of allocation concealment (selection bias).

ๆSmall number of participants and wide confidence intervals.

${ }^{* *}$ Risk of bias due to lack of blinding of participants and personnel (performance bias).

††Risk of bias due to incomplete outcome data (attrition bias).

telemedicine in multimorbidity is limited and interventions have rarely been evaluated in a systematic fashion. In spite of the considerable role digital telemedicine has taken in public and professional debates in healthcare over the last 15 years, the implementation of digital telemedicine interventions for patients with multimorbidity cannot be recommended because of the weak evidence. Where health services are implementing, it seems sensible to integrate interventions with usual care and adapt them to the local context to not inappropriately divert resources from alternative, non-digital approaches.
After implementation, continuous evaluation will help improve practice and also add to the still small evidence base for digital telemedicine for multimorbidity. It is important to ensure interventions are implemented with relevant outcome parameters, determined ideally by taking into account the preferences of patients and healthcare providers and in the best interest of society and the overall health systems and not just as assumed progressive prestige projects. Future high-quality interventional research is needed that includes longer periods of follow-up and should investigate which components of 
telemedicine are most effective and how usual care, in and across sectors, can best be integrated avoid inappropriately diverting resources from alternative, non-digital approaches. It should be considered to include realistic evaluation approaches because of the importance that particular contextual factors could have on the implementation effectiveness of the interventions of interest. We anticipate that more evidence will become available in the future requiring updates of this review to inform policy makers and research appropriately.

Contributors All authors were involved in the design and concept of the study. CK and CF conceived and designed the study. CK conducted the systematic literature search and data extraction, conducted the analyses and wrote the manuscript. MvdM was involved in the systematic literature search and data extraction. CF is the guarantor.

Funding The authors have not declared a specific grant for this research from any funding agency in the public, commercial or not-for-profit sectors.

Competing interests None declared.

Patient and public involvement Patients and/or the public were not involved in the design, or conduct, or reporting or dissemination plans of this research.

Patient consent for publication Not required.

Provenance and peer review Not commissioned; externally peer reviewed.

Data availability statement All data relevant to the study are included in the article or uploaded as supplementary information. All data relevant to the study are included in the article or uploaded as supplementary information. No additional data available.

Open access This is an open access article distributed in accordance with the Creative Commons Attribution Non Commercial (CC BY-NC 4.0) license, which permits others to distribute, remix, adapt, build upon this work non-commercially, and license their derivative works on different terms, provided the original work is properly cited, appropriate credit is given, any changes made indicated, and the use is non-commercial. See: http://creativecommons.org/licenses/by-nc/4.0/.

ORCID iD

Christian Kraef http://orcid.org/0000-0002-5224-0335

\section{REFERENCES}

1 Onder G, Palmer K, Navickas R, et al. Time to face the challenge of multimorbidity. A European perspective from the joint action on chronic diseases and promoting healthy ageing across the life cycle (JA-CHRODIS). Eur J Intern Med 2015;26:157-9.

2 Melchiorre MG, Lamura G, Barbabella F, et al. eHealth for people with multimorbidity: Results from the ICARE4EU project and insights from the '10 e's' by Gunther Eysenbach. PLoS One 2018;13:e0207292.

3 Maeng DD, Martsolf GR, Scanlon DP, et al. Care coordination for the chronically ill: understanding the patient's perspective. Health Serv Res 2012;47:1960-79.

4 Smith SM, Wallace E, O'Dowd T, et al. Interventions for improving outcomes in patients with multimorbidity in primary care and community settings. Cochrane Database Syst Rev 2016;3:CD006560.

5 Starfield B. New paradigms for quality in primary care. $\mathrm{Br} J \mathrm{Gen}$ Pract 2001;51:303-9.

6 Wyatt KD, Stuart LM, Brito JP, et al. Out of context: clinical practice guidelines and patients with multiple chronic conditions: a systematic review. Med Care 2014;52:S92-100.
7 WHO. WHO Guideline: recommendations on digital interventions for health system strengthening [online]. Available: http://www.who.int/ reproductivehealth/publications/digital-interventions-health-systemstrengthening/en/ [Accessed 30 Oct 2019].

8 Shamseer L, Moher D, Clarke M, et al. Preferred reporting items for systematic review and meta-analysis protocols (PRISMA-P) 2015: elaboration and explanation. BMJ 2015;349:g7647.

9 Stevenson JK, Campbell ZC, Webster AC, et al. eHealth interventions for people with chronic kidney disease. Cochrane Database of Systematic Reviews [online], 2016. Available: https://www. cochranelibrary.com/cdsr/doi/10.1002/14651858.CD012379/abstract [Accessed 3 Mar 2019].

10 Meystre S. The current state of telemonitoring: a comment on the literature. Telemed J E Health 2005;11:63-9.

11 Perez D, Memeti S, Pllana S. A simulation study of a smart living IoT solution for remote elderly care. In: 2018 third International Conference on FOG and mobile edge computing (FMEC), 2018: 227-32.

12 McGowan PT. Self-management education and support in chronic disease management. Prim Care 2012;39:307-25.

13 Hoffmann TC, Glasziou PP, Boutron I, et al. Better reporting of interventions: template for intervention description and replication (TIDieR) checklist and guide. BMJ 2014;348:g1687.

14 Johnston MC, Crilly M, Black C, et al. Defining and measuring multimorbidity: a systematic review of systematic reviews. Eur J Public Health 2019;29:182-9.

15 Yoo HJ, Park MS, Kim TN, et al. A ubiquitous chronic disease care system using cellular phones and the Internet. Diabet Med 2009;26:628-35.

16 Wakefield BJ, Holman JE, Ray A, et al. Outcomes of a home telehealth intervention for patients with diabetes and hypertension. Telemed J E Health 2012;18:575-9.

17 Wakefield BJ, Holman JE, Ray A, et al. Effectiveness of home telehealth in comorbid diabetes and hypertension: a randomized, controlled trial. Telemed J E Health 2011;17:254-61.

18 Donesky D, Selman L, McDermott K, et al. Evaluation of the feasibility of a home-based TeleYoga intervention in participants with both chronic obstructive pulmonary disease and heart failure. $J$ Altern Complement Med 2017;23:713-21.

19 Bernocchi P, Vitacca M, La Rovere MT, et al. Home-based telerehabilitation in older patients with chronic obstructive pulmonary disease and heart failure: a randomised controlled trial. Age Ageing 2018;47:82-8.

20 Rifkin DE, Abdelmalek JA, Miracle CM, et al. Linking clinic and home: a randomized, controlled clinical effectiveness trial of real-time, wireless blood pressure monitoring for older patients with kidney disease and hypertension. Blood Press Monit 2013;18:8-15.

21 Mira JJ, Navarro I, Botella F, et al. A Spanish pillbox APP for elderly patients taking multiple medications: randomized controlled trial. $J$ Med Internet Res 2014;16:e99.

22 McManus RJ, Mant J, Haque MS, et al. Effect of self-monitoring and medication self-titration on systolic blood pressure in hypertensive patients at high risk of cardiovascular disease: the TASMIN-SR randomized clinical trial. JAMA 2014;312:799-808.

23 Omboni S, Ferrari R. The role of telemedicine in hypertension management: focus on blood pressure telemonitoring. Curr Hypertens Rep 2015;17:535.

24 Zhai Y-kai, Zhu W-jun, Cai Y-ling, et al. Clinical- and costeffectiveness of telemedicine in type 2 diabetes mellitus: a systematic review and meta-analysis. Medicine 2014;93:e312.

25 Free C, Phillips G, Watson L, et al. The effectiveness of mobile-health technologies to improve health care service delivery processes: a systematic review and meta-analysis. PLoS Med 2013;10:e1001363.

26 Thabrew $\mathrm{H}$, Stasiak K, Hetrick SE, et al. E-Health interventions for anxiety and depression in children and adolescents with longterm physical conditions. [Review]. Cochrane Database Syst Rev 2018;1:CD012489.

27 Bower P. Better management of multimorbidity: a critical look at the 'Ariadne principles'. BMC Med 2014;12:222. 